Arhe XVII, 33/2020

UDK 159.954 Ortega y Gasset

124.4

DOI https://doi.org/10.19090/arhe.2020.33.221-242

Originalni naučni rad

OriginalScientificArticle

TANJA TODOROVIĆ ${ }^{1}$

Univerzitet u Novom Sadu, Filozofski fakultet

\title{
FANTAZIJA I STVARALAŠTVO U GASETOVOJ FILOZOFIJI
}

Sažetak: Ortega i Gaset nema sistemski razvijenu filozofiju. Stoga se pojmovi fantazije i stvaralaštva u ovom radu interpretiraju u okvirima njegovih ontoloških istraživanja i u kontekstu njegovih refleksija o „novoj“, „mladoj“, avangardnoj umetnosti. Pokazaće se da fantazija za njega za razliku od tradicije ne predstavlja poseban „organ“ ili momenat u teoriji saznanja, nego je jedan od fundamentalnih načina na koji se čovek odnosi prema svetu. Čovek se shvata kao putnik, homo viator, čiji je zadatak da interpretativno uobličava sopstvenu realnost. Zahvaljujući fantaziji čovek ima interpretativan odnos prema životu, a u savremenom svetu počinje da ima i prema samim umetničkim delima. Sa druge strane, ispostavićemo njegovu kritiku pojma stvaralaštva na temelju filozofije umetnosti, i re-afirmisanje ovog pojma u kontekstu racional-vitalističke pozicije. Ključne reči: dehumanizacija, fantazija, interpretacija, Ortega i Gaset, mase, stvaralaštvo

\section{ONTOLOŠKI OKVIR ISTRAŽIVANJA}

Gaset je imao nekoliko perioda u svom svaralaštvu, međutim, njegova filozofija nikada nije dobila sistemski oblik. Najčešće se njegovo delo svrstava u racional-vitalizam, iako do ovog koncepta on dolazi tek u zrelijem periodu stvaralaštva. Zbog toga kada pristupamo razmatranju određenih pojmova u njegovoj filozofiji treba da budemo veoma oprezni. Osnovna ideja njegove filozofije se temelji na nekim osnovnim uvidima

\footnotetext{
${ }^{1}$ E-mail adresa autorke: tanja.todorovic@ff.uns.ac.rs
} 
Ničeovog vitalizma i Huserlove fenomenologije. Od Ničea preuzima ideju da racionalnost treba da bude usmerena tako da služi životu, a ne da mu šteti.Tako pokazuje da je čovek pre svega biće fantazije, imaginacije, biće čiji je zadatak da oblikuje istinu svog sveta, jer mu ona nije unapred data. Mogućnosti dolaze iz života, čovek je biće koje ih uobličava i ostvaruje. Huserl, sa druge strane, pojam fantazije razmatra na temelju ispitivanja struktura subjektivnosti. ${ }^{2}$ Razlika spram Huserlovih razmatranja pojma mogućnosti $u$ kontekstu preispitivanja modifikabilnosti pojave $\mathrm{e}^{3}$ ogleda se u preispitivanju ovog pojma ne samo u cilju iznalaženja čiste nauke subjektivnosti, već preispitivanja pojma mogućnosti u najširem smislu te reči. Stoga se pojam mogućnosti razmatra u kontekstu odnosa subjektivnosti i sveta u kome poslednji stupanj, redukcija, više ne može da ima pravo na ispostavljanje suštinske odlike predmeta. Gaset pokušava da misli život u procesualnosti, što znači staviti čoveka u poziciju u kome je on aktivni stvaralac svog sveta, a ne pasivni reagens na opšte ideje duha vremena. Tako, ako bi se držao fenomenološkog imperativa „od pojave ka samim stvarima“ on bi zapravo zaključio da se nikada ne dolazi do one jedne stvari, koja je u osnovi svih stvari. Upravo se iz ,intimizarane“ subjektivnosti kreće ka stvarima. Za subjektivnost je primarno pitanje ne o istini same stvarnosti, već o tome kako živeti u stvarnosti bez apsolutne istine u vidu činjenične datosti. I na prvi pogled Gasetov projekat deluje hajdegerijanski, međutim, on pravi otklon i od njegovih ideja pokazujući da nauka o biću poput fundamentalne onologije ne može biti ostvarena. Za razliku od Hajdegera koji stavlja akcenat na ispitivanje fantazije u kontekstu kritike tradicionalne metafizike ${ }^{4}$, Gaset stavlja akcenat na sadašnjost bez potrebe da se razračunava sa prošlošću. Razračunavanje sa prošlim filozofijama

${ }^{2}$ Intencionalna analza je otkrivanje aktualnosti i potencijalnosti u kojima se predmati konstituišu kao osetilna jedinstva, a svaka osetilna analiza vrši se u prelazu iz zbiljskih doživljaja u intencionalne horizonte koji su u njima unapred naznačeni. Upor.: Kartezijanske meditacije 1, Centar za kulturnu delatnost Saveza socijalističke omladine, Zagreb, 1975, str. 26-27.

${ }^{3}$ Husserl, Edmund. Ideja fenomenologije, pet predavanja, Beogradski izdavačkografički zavod, Beograd, 1975, str. 26.

${ }^{4}$ Ovo je posebno vidljivo u delu „Kant i problem metafizike“. Upor. Hajdeger, Martin. Kant i problem metafizike, Mladost, Beograd, 1979. 
je samo još jedan korak ka priznavanju istih, kritika stare metafizike najčešće vodi ka uspostavljanju nove, stoga on pokušava da napravi drugačiju filozofiju u čijoj osnovi neće biti ispostavljene nove strukture subjektivnosti ili mrtvi egzistencijali, već jedna dinamična konstrukcija u čijem središtu je čovek. Suštine predmeta se konstituišu u kretanju subjekta i sveta. Pojam je način da se čovek suoči sa realnošću, što znači da $\mathrm{u}$ svakom teorijskom stavu postoji jedna vrsta praktičnoegzistencijalnog nastojanja. Ne postoji „„cista nauka“ koja može biti neutralna naspram sveta života.

Gaset, slično kao i drugi fenomenolozi, razmatra pojam mogućnosti u kontekstu pojma fantazije, pokazujući da ostvarivanje mogućnosti dolazi delimično iz aktivnosti same subjektivnosti, delimično iz samog sveta. Ovaj pojam se u savremenosti razlikuje od aristotelovski shvaćenog pojma dynamisa. Za Gaseta najvišu istinu su imali predsokratovci, i posebno afirmiše Heraklita i Parmenida $u$ tom kontekstu. ${ }^{5}$ Oni su promišljali „ogoljen život“ koji se događa u susretu čoveka i bića. U njemu celina ostaje zauvek nedostupna, što ne znači da se čovek ne nalazi na putu njenog otkrivanja. Život je sastavljen od razlika i promena i od cele realnosti čovek samo deo zahvata. Čovek na početku misli da „ima same stvari“, ali sve što on ima jesu ideje o njima. To znači da on nema neposredan uvid u realnost, već da se prema njoj uvek već odnosi kroz seriju slika i uverenja. Na početku čovek označava stvari i ima jednostavne ideje o svetu, međutim on je sklop uverenja i navika koje u tom svetu usvaja. Čovek postaje polako uverenja koja živi: „Mi sa uverenjima ne činimo ništa, mi jednostavno jesmo naša uverenja. ${ }^{\text {“6 }}$ Kao što se re-definiše pojam mogućnosti tako se re-definiše i pojam stvaralaštva $u$ najširem smislu te reči. Biti stvaralac znači biti u kretanju, biti u aktivnosti, biti u procesu. ${ }^{7}$ Gaset će pokazati da se pojam

${ }^{5}$ Ortega y Gasset, José and Talbot, Toby. The origin of philosophy. North \& Company, New York, 1967, p. 51.

${ }^{6}$ Gasset, José y Ortega. Ideas y creencias. Revista de Occidente, Madrid, 1934. pp. 381-409.

${ }_{7}^{7}$, ,Stvaralac jednog dela na izvestan način postoji u svom aktu svaranja, u svom delu. On voli svoje delo zato što voli svoje postojanje, i to je prirodno, jer ono što je neko kao mogućnost, to delo svojim ostvarenjem pretvara $u$ 
stvaranja izmešta u područje intersubjektivnih relacija. Svet umetnosti i filozofije postaje svet konstrukcije, fantazije i mogućnosti. Ako čovek nema neposredan uvid u realnost, onda je njegov odnos intrepretativan. Pojam interpretacije postaje važan kako u određivanju ostvarivanja mogućnosti pojedinačnog života, tako i u odabiru koja se tačka gledišta uzima za relevantnu u tumačenju umetničkog dela.

U Gasetovoj filozofiji je moguće, sa jedne strane, pokazati otklon od koncepta stvaralaštva iz perspektive filozofije umetnosti, dok, sa druge strane, on ovaj pojam oživljava u svojim razmatranjima o konkretnoj ljudskoj egzistenciji i pitanju smisla života u najširem smislu te reči. Istražujući logički tok istorije slikarstva on vrši dekonstrukciju pojma stvaralaštva, očuvavajući njegov smisao samo u kontekstu zajednice, onog praktičkog, dinamičkog i egzistencijalnog na temelju pojma intersubjektivnosti. Poreklo pojma „stvaranje“ (lat. creatio) je hrišćansko, i paradoksalno se pokazuje da iako se u hrišćanstvu čovek shvatao dominantno kao stvaralačko biće, da je tada filozofija umetnosti u najmanjoj meri bila samostalna i razvijena. Ideja i realnost su u ovom periodu u ambivalentnom odnosu. Bilo da je shvaćen kao natura naturans $^{8}$, kao produžetak prirode čija je suštinska odlika da stvara, ili kao slika božija $a^{9}$ koja po ugledu na boga kreira, u različitim periodima srednjeg veka se čovekova esencija crpela iz transcendensa. Renesansa očuvava ontološki okvir hrišćanstva, uvodeći u njega „nove“ ideje i sadržaje iz antike. Time je doprinela da se hrišćanski pojam stvaralaštva „materijalizuje“, da se čovek pokaže kao konkretno stvaralačko biće. To je imalo za posledicu da se srednjovekovna formalistička metafizika otopi i zapečati u novom ruhu uspona prirodne nauke. Iako, kako Gaset

stvarnost.“ Aristotel. Nikomahova etika, Izdavačka knjižarnica Zorana Stojanovića, Sremski Karlovci-Novi Sad, 2013, str. 195.

${ }^{8}$ Kod Eriugene, a kasnije i kod Spinoze, Bog se shvata kao stvaralačka aktivna priroda, a čovek kao stvorena priroda koja i sama ima mogućnost stvaranja. Upor : Eriugena, Johanes. „O podeli prirode“, u: Od Aristotela do renesanse, Nakladni zavod Matice hrvatske, Zagreb, 1982, str. 221.

9 Anselmo čoveka eksplicitno shvata kao sliku božiju. Videti: Kantarberijski, Anselmo. „Proslogion“, u: Quid vere sit Deus, Demetra, Zagreb, 1977, str. 155. 
pokazuje, savremeni period po filozofskoj krizi dosta sliči na renesansu ${ }^{10}$, $\mathrm{u}$ renesansi na kraju pobeđuje racionalni princip, na osnovu koga se čovek dominantno shvata kao homo faber. ${ }^{11}$ Tako se pojam stvaralaštva sekularizuje i nužno dovodi u vezu sa drugim oblicima egzistiranja, u kojima je proizvodnja jedan od značajnih momenata prosvetiteljske racionalizacije.

Moderna filozofija, koja nastaje kao produžena ruka dominantne racionalnosti, čoveka primarno razumeva kao saznajno biće. Pobeda teorijskog uma pod načelom prirode je doprinela osiromašenju nekih pojmova koji su bili višeznačni $u$ antici i re-interpretaciji iste $u$ renesansi. Umetnost svoj put nastavlja u svakoj epohi, kako je Hegel to pokazao, izražavajući duh sopstvenog vremena, ali čovek se ne shvata uvek primarno kao stvaralačko biće. Tek Kant izokreće moderne formalne podele ljudske prirode i pokazuje da je čovek primarno delatni subjekt. Hegel onda pokazuje čoveka kao konkretno delatno biće, stvaralačkog subjekta. ${ }^{12}$ Gaset će kritikovati idealizam pokazujući da ne postoji tako nešto kao što je „apsolutna ideja“ u kojoj se čovek kroz delatnost refleksivnim moćima „stapa“ i u kojoj se sve protivrečnosti razrešavaju. Svaka ideja je samo relativna i nastaje kao posledica i rezultat borbe čoveka sa svetom, borbe da se izrazi i snađe u svetu. Svaka ideja je plod čovekove stvaralačke fantazije:

„Za antičare, realnost, jestanje je bilo 'tvar'; za moderne mislioce
jestanje je značilo 'intimiziranu subjektivnost'; a za nas, jestanje znači
'živeti' - što će reći intimnost ne samo sa samim sobom već i
stvarima. [...] Danas kažemo da je radikalna datost moja
koegzistencija sa stvarima. Ali čim to kažemo pravimo grešku jer
postajemo svesni da dominira 'koegzistencija' kao modus odnošenja
spram sveta, ta primarna realnost, koja je istovremeno unitarna i
dvostruka, ta veličanstvena činjenica koja je u svojoj suštini dualizam.
Jer koegzistencija znači upravo to da jedna stvar egzistira zajedno sa
drugom, da jeste jedno i drugo. Estatički karakter, koji podleže

${ }^{10}$ Gasset, José y Ortega. En torno a Galileo, Esquema de la Crisis, Revista de Occidente, 1976, p. 28.

${ }_{11}^{11}$ Što ćemo kasnije videti da nije slučaj sa savremenim svetom.

${ }^{12}$ Upor. Buber, Martin, and Eugenio Ímaz. ¿Q Qué es el hombre?. Fondo de Cultura Económica, Mexico, 1949, p. 42. 
između bivanja i jestanja, ova dva stara koncepta, uvek već falsifikuje ono što želimo izraziti.“'13

Ovaj pasus koji smera direkno na kritiku idealizma, pokazuje da kretanje nije moguće zaustaviti u apsolutnoj ideji. Da tako nešto kao što je čista ideja ili činjenica realnosti ne postoji. Ono što je primarno jeste odnos, koji je za čoveka samo delimično uhvatljiv. To je ontološka prizma kroz koju Gaset, kao i neki drugi savremni mislioci, ispituje između ostalog i pojam stvaranja. Ne postoji apsolutna istina koju bi čovek mogao da sazna pa da odredi spram nje kako da živi. Zbog toga je život „drama“ jer orijentir je nešto što čovek u hodu smišlja. Što se tiče usko pitanja vezanog za filozofiju umetnosti, tu se pokazuje da je čovek upravo postao delatnik na temelju prinicipa raz-stvarivanja sveta, ne njegovog raš-čaravanja, već naprotiv njegovog sve većeg otuđivanja.

Pored kritike modernog načina mišljenja, za koje na kraju kaže da je ipak iz perspektive istorije moralo biti nužno, Gaset kritikuje i romantizam. Smatrajući da romantičarske ideje postaju plodne za uspon afirmativne kulture, Gaset pravi otklon od njih i blagonaklono se odnosi prema novim umetničkim pokretima. On izbegava tako mnogo zastupljen pojam ,avangarda“ iz prostog razloga što se u tom periodu mnogi pokreti nisu dovoljno uobličili da bi dobili svoj suštinski naziv koji ne bi bio problematičan. ${ }^{14}$ On sve vreme komunicira sa idejom „nove umetnosti““15 koja donosi svežinu i „nove ideje“ fundamentalno različite od svih prethodnih perioda. Postoji tačka u kojoj se njegovo razmatranje savremene umetnosti poklapa sa njegovom filozofskom teorijom, koju nije najjednostavnije izložiti iz prostog razloga što Gaset nije sistemski, pre je esejski mislilac. Ta tačka je upravo odnos subjekta i sveta, ili bolje rečeno intersubjektivni odnos spram sveta koji uključuje nužno u sebe punto de vista onog koji posmatra određenu stvar, čija intencionalnost nužno biva uvučena u zajednički horizont konstituisanja realnosti. Gaset kritikuje kod Huserla ideju čiste nauke i mogućnost redukcije kao

${ }^{13}$ Prev. autor. Videti: Gasset, José y Ortega. „¿Qué es filosofía?“, en : Obras Completas, Revista de Occidente, 405(1969) 8, Madrid, p. 405.

${ }^{14}$ Poggioli, Renato. The Theory of the Avant-garde, Harvard University Press, Cambrige, 1968, p. 05.

${ }^{15}$ Još: ,,dehumanizovane umetnosti“, ,apstraktne umetnosti“, „,mlade umetnosti“. 
metodološkog oblika kojim se saznaju konačne suštine svari. Ipak, on od njega preuzima koncept intersubjektivnosti u okviru ideje intermonadologijskog poretka sveta. $^{16}$ Nije reč, dakle, o modernom Lajbnicovom konceptu monadologije, već o tome da se subjektivizam kroz intersubjektivnost prevaziđe. Monade su upravo te gore pomenute „intimizirane subjektivnosti“ koje se nalaze u konstantnom odnosu sa stvarima i među sobom. Termin monada izražava dvostrukost onoga što Gaset u svojim esejima negde direktno, negde indirektno zaključuje:

1. U savremenoj umetnosti je akcenat na percepciji, važan je punto de vista samog umetnika, ali i posmatrača koji biva uvučen u proces interpretacije dela. Tako je pojam fantazije ključan za savremeni svet jer je on posrednik u novim intersubjektivnim konstruktima istine.

2. U savremenom svetu čovek je kreator i stvaralac sopstvenog sveta samo uslovno jer njegova delatnost nužno zavisi od stepena percepcije i komunikacije sa opštim idejama, te „stapanja“ ili otklona u odnosu na njih.

Stoga je i sam rad strukturalno podeljen na dva dela. Prvi, koji pokušava izraziti Gasetov odnos prema savremenoj umetnosti u kojoj se rekonstruiše tradicionalni pojam fantazije i stvaralaštva. I drugi, koji onda daje ontološki okvir Gasetove teoriije kroz razmatranje pojma stvaralaštva u najširem smislu ključnih dela njegove filozofije.

\section{UMETNOST I STVARALAŠTVO}

Gaset možda među prvim autorima reflektuje nove umetničke pokrete koji niču početkom dvadesetog veka. On ne pokušava da zasnuje estetiku kao čistu naučnu disciplinu iz prostog razloga što generalno u svojim spisima pravi otkon od takve vrste naučnosti smatrajući da je ona

16 Huserl pokazuje da se smisao ljudske zajednice kreira u uzajamnom postojanju, u sa-postojanju sa drugima $\mathrm{i}$ da zajednici $\mathrm{u}$ transcendentalnoj konkretnosti odgovara adekvatna, otvorena zajednica monada, transcendentalna intersubjektivnost. Videti: Huserl, Edmund. Kartezijanske meditacije 1, Centar za kulturnu delatnost Saveza socijalističke omladine, Zagreb, 1975., str. 142. 
posledica modernog načina mišljenja koje se nastoji preneti na sve sfere realnosti. Za njega nauka u najširem smislu predstavlja interpretaciju činjenica $^{17}$ koje nije moguće svesti na jednu jedinu stvar (res) kako su to pobornici novovekovnog racionalizma i empirizma mislili. Pojam interpretacije se usvaja ne samo u strogo naučnom smislu. Valja pokazati da i sam život, i umetnička dela koja sada njega uzimaju za svoj vodeći „princip“ podležu interpretaciji. Još, interpetacija zavisi od percepcije, pa se tako pokazuje da je za umetnika koji stvara važno koji ugao posmatranja bira da izrazi određenu stvar. Stvarnost postaje praktična i normativna, kako za za samog umetnika, tako i za posmatrača. To znači da tačka gledišta umetnika, a naknadno, i interpretatora postaje proizvoljna. $^{18}$

Dok je modernost imala poverenja u sistemski način mišljenja očvrsnut neophodnom metodologijom, savremeni mislioci se nalaze na jednom uzdrmanom tlu: „Modernost je samopouzdana, ona duboko veruje $\mathrm{u}$ istinu vlastitog razvoja $\mathrm{u}$ vremenu [...] Njoj nasuprot, savremenost je sva u znaku nervoze, slabosti i nespokojstva. ${ }^{\text {“19 }}$ Kriza nauke nije samo kriza pozitivne nauke, već je ona u savremenom svetu zahvatila sve sfere duha. Kriza je promena u kojoj čovek ne može da se snađe. On ne može više da kreira vlastiti horizont kada stvari koje se dešavaju oko njega prevazilaze potpuno mogućnost da ih reflektuje i uobliči u celovit sistem. ${ }^{20}$ Upravo se to događa u savremenosti. Kriza je vidljiva u mnogim teorijskim područjima, a u praktičnom svetu je eskalirala i sukobima svetskih razmera. Šta to znači za samo stvaralaštvo? U razmatranju problema krize i perspektive umetnosti treba imati u vidu dva sloja tumačenja: prvi se odnosi na način na koji umetnici stvaraju, a drugi na način na koji mase percipiraju tj. reaguju na nova umetnička dela.

Umetnost dvadesetog veka nije jednostavno označiti upravo zbog toga što ona ne predstavlja jedan školski uobličen sistem, već se sastoji iz

\footnotetext{
${ }^{17}$ Gasset, Jose y Ortega. En torno a Galileo, Esquema de la Crisis, p. 4.

${ }^{18}$ Gaset, José y Ortega. Dehumanizacija umetnosti $i$ drugi eseji, LITTERIS, Zagreb, 2007, str. 25.

19 Prole, Dragan. Pojave odsutnog, Izdavačka knjižarnica Zorana Stojanovića, Novi Sad-Sremski Karlovci, 2016., str. 8.

${ }^{20}$ Gasset, Jose y Ortega. En torno a Galileo, Esquema de la Crisis, p. 33.
} 
mnoštva različitih pokreta, koji, svaki za sebe, ima neku svoju unutrašnju dinamiku. Ipak, postoji nešto što je zajedničko tim novim umetničkim pokretima a to je kritički i afirmativan odnos prema realnosti koji se u tim delima često i simultano pojavljuje. ${ }^{21}$ Doći do istine vlastitog vremena ne znači prihvatiti sve što se događa u sadašnjosti kao najbolju moguću verziju realnosti. Naprotiv. Umetnost čija je primarna uloga težnja ka istini $^{22}$, treba da ima ulogu i da raskrije neistinosti vlastitog vremena. Avangarda je u tom kontekstu možda pokazala i najveću svoju snagu. Iako se ona u literaturi optužuje da je usmerena protiv toga da se sadašnjost shvati u kontinuiranom odnosu spram prošlog, možda je bolje tvrditi da je ona usmerena protiv lažnog i ideloškog predstavljanja prošlog. Ona možda ne želi više da bude samo deo određenog duha vremena, već da izrazi osnovne momente života kao ono što je zajedničko svim duhovnim formama kroz istoriju. Ukratko, ona nije aistorijski nastrojena, već želi dekonstruisati pogrešne predstave o istoriji. ${ }^{23}$ Ako je sadržina koju ona nastoji izraziti jedinstvo univerzalnih životnih vrednosti, koje su u savremenosti očigledno u krizi, onda ona to mora učiniti tako da se postavi u antagonizmu spram duha vlastitog vremena. Taj antagonizam je samo naizgledan, jer se pokazuje da je njen suštinski cilj i dalje da dođe do više istine. U tom kontekstu Gasetova priča o dehumanizaciji umetnosti bi valjalo da bude shvaćena pozitivno. ${ }^{24}$ Kako uopšte shvatiti taj proces?

Hegel je u svojoj kritici Kantove estetike pokazao da ideal prirodno lepog mora da se povuče i ustupi mesto artificijalnom jer je to sfera apsolutnih duhovnih istina. Gaset, sa druge strane, želi da pokaže da je o ljudskim vrednostima moguće govoriti i ironično kroz proces dehumanizovanja umetnosti. „Novi stil“, kako ga on naziva, ima neke od

\footnotetext{
${ }^{21}$ Poggioli, Renato. The Theory of the Avant-garde, p.24.

${ }^{22}$ Sve druge uloge moraju imati sekundarni značaj, kao što je terapijska, zabavna i utilitaristička upotreba umetnosti, kako je još Hegel pokazao.Upor.: Rajković, Marica. „Kraj umetnosti kao početak estetike“, u: Estetika $i$ obrazovanje, Estetičko društvo Srbije, Beograd, 2011., str. 21.

${ }^{23}$ Habermas, Jürgen. „Modernity - An Incomplete Project“, in : Foster, H. The anti-aesthetic: Essays on postmodern culture, Bay Press, Washington, 1983, p. 5.

${ }^{24}$ Poggioli, Renato. The Theory of the Avant-garde, p.175.
} 
sledećih karakteristika: dehumanizira umetnost, izbegava žive oblike, sve nastoji predstaviti kroz jedno delo, umetnost shvata kao igru koja je svet zatvoren u sebe, ironija se koristi kao sredstvo, umetnici nastoje izbeći laž vlastitog vremena, i na samome kraju mladi ljudi je moraju moći shvatiti bez povezivanja sa transcendensom. ${ }^{25}$ Ono što je zajedničko filozofiji i avangardi u ovom kontekstu je upravo pokušaj da se manjkavosti stvarnosti povezuje sa modernim načinom mišljenja koje je u svojoj srži antropocentrično i evropocentrično. U filozofiji ${ }^{26}$ još uvek postoji pokušaj „očuvavanja“" nekih pozitivno-naučnih ideala, međutim, umetnost je definitivno što $u$ jedinstvu, što $u$ razlici spram romantizma napravila otklon od fundamentalnih modernih ideala. Dehumanizacija ne znači anti-humanizam, već praksu izbegavanja da se ono ljudsko predstavlja na platnu i u delima. Čovek ne uzima sebe više kao predmet sopstvenog sveta, bar ne u literarnom smislu. Oblici koje ona predstavlja su manje ili više jasni, ali se ne vidi nužno na prvi pogled njihova povezanost sa duhom sopstvenog vremena. Deluje kao da umetnik ide protiv čoveka, protiv živih oblika, protiv stvarnosti. ${ }^{27}$

Gaset pokazuje tako da stvaralačka fantazija nije neki mrtvi organ kojim se čovek služi, nego njegova osnovna sposobnost da očuva svoju vitalnost. Drugim rečima, fantazija pomaže čoveku onda kada više ne može da prihvati zatečenu stvarnost, već je prinuđen da ,ide protiv date realnosti“. Umetnik nema više zadatak da naslika stvar u jedinstvu sa drugim stvarima, čoveka u jedinstvu sa dugim ljudima, koegzistenciju stvari i ljudi, već upravo je njegov zadatak da kroz umetničko delo komunicira sa drugima predstavljajući ono što je njegov aspekt realnosti koji referiše na određen događaj. To znači da realnost, ili duh vremena, nije izbačen iz umetničkih dela, već da je forma njegovog izražavanja postala drugačija. Ona nije direktna slika realnosti čak i kada referiše na realan događaj. Tako na primer, ako pogledamo čuvenu Pikasovu Gerniku, na osnovu istorijskog konteksta nam je veoma jasno šta i kako ona izražava, način i stil izražavanja umetnika su postavljeni tako da budu otvoreni prema posmatraču, koji naknadno treba da doživi i

\footnotetext{
${ }^{25}$ Gaset, José y Ortega. Dehumanizacija umetnosti i drugi eseji, str. 25.

${ }^{26}$ Kao kod Huserla na primer.

${ }^{27}$ Gaset, José y Ortega. Dehumanizacija umetnosti i drugi eseji, str. 35.
} 
komunicira sa delom. Vreme, prostor i oblici figura su definitivno drugačije predstavljeni $\mathrm{u}$ odnosu na tradiciju, međutim, upravo $\mathrm{u}$ toj drugačijosti treba da se izraze univerzalne životne vrednosti koje $\mathrm{u}$ samom događaju nisu prisutne. Naprotiv, događaj se predstavlja u kontrastu spram njih, i tako se laž vlastitog vremena raskriva kroz ono što bi bila univerzalna životna istina. U tom kontekstu ne možemo nazvati savremenu umetnost „lažnom“ kada je njena uloga upravo da kroz dela raskrije lažne predstave vlastitog vremena. Ipak te „univerzalne vrednosti“ nisu u samim objektima već u subjektu. Zbog toga je važan subjekat kao stvaralac samo uslovno, jer on nema više zadatak da predstavi neposrednu sirovu materijalnu građu, već se tačka njegovog gledišta uvlači $u$ proces predstavljanja realnosti. Zbog toga $u$ razumevanju umetničkih dela $\mathrm{u}$ savremenosti nije presudno shvatiti proces stvaralaštva umetnika već tačku gledišta samog umetnika, sa jedne strane, i način na koji se delo onda percipira, sa druge.

\section{O TAČKI GLEDIŠTA U UMETNOSTIMA}

U ovom delu rada dolazimo do ključnog i najtežeg problema u Gasetovom shvatanju umetnosti a to je odnos savremene umetnosti (i filozofije) prema istoriji. Hegelova najava „kraja umetnosti“, koja se povezuje sa najavom kraja filozofije, u literaturi se interpretira na različite načine. ${ }^{28}$ Iako pravi otklon od idealizma, Gaset pokazuje nužnost veze filozofije i likovne umetnosti u istoriji. On ide i korak dalje od Hegela, želeći da pokaže da filozofija i likovna umetnost imaju i u savremenosti zajedničku tačku, a to je način predstavljanja same stvarnosti. One i dalje imaju isti sadržaj, ali to više nije apsolutna ideja, jer ne može da bude, već je istina shvaćena kao intersubjektivna konstrukcija. Ta intersubjektivna konstrukcija ima svoje utemeljenje u životnim vrednostima koje prevazilaze područje ljudskog saznanja, stoga ne predstavljaju nikakvu stvar iz koje je spinozistički moguće dedukovati svet već samo donkihotovski postavljenu težnju čoveka da ih postigne.

\footnotetext{
${ }^{28}$ Kao što se u prethodnom pasusu i nastojalo pokazati. Upor. Rajković, Marica. „Umetnost i duh vremena“, u: Kriza umetnosti $i$ nove umetničke prakse, Estetičko društvo Srbije, Beograd, 2014., str. 247.
} 
Fantazija tako postavlja ideale kojima teži, a koje nije moguće pronaći u zatečenoj realnosti.

Gasetovo čuveno delo „O tački gledišta u umetnostima“ pokazuje kako je umetnost prešla put od predstavljanja „neposredne“ stvarnosti do predstavljanja stvarnosti kroz sopstveni puno de vista umetnika. To više nije apstraktna umetnost već je intimizirana umetnost. To nije ono najneposrednije subjektu, to je ono najudaljenije od njega. ${ }^{29} \mathrm{Na}$ samom početku ovog teksta vidi se da se u savremenoj recepciji istorija više ne hvata kao sistem već kao realnost koja teče kao reka koju umetnik-filozof nastoji zamrznuti. ${ }^{30}$ On pokazuje kako je došlo do progresivne derealizacije sveta $u$ istoriji filozofije, koja se dogodila tako što se tačka gledišta umetnika pomerala od stvari ka samom umetniku. Posmatraču istorije likovne umetnosti deluje da se menja način na koji se tela predstavljaju, ali se suštinski menja tačka gledišta onoga koji predstavlja delo. I dok je ta tačka u modernoj filozofiji vezana za same stvari koje se shvataju kao komadi, krupna tela, često dvodimenzionalni prikazana, u savremenosti se više ne slikaju tela već način na koji se ona percipiraju. Subjektivna tačka gledišta biva uvučena u način predstavljanja realnosti, te time želi da se pokaže ono što je Huserl već nagovestio, a to je da objektivnost $i$ ne postoji bez subjekta. Realnosti se ne oduzima samo njena esencijalnost, nego se mešaju suštinske i akcidentalne odlike ${ }^{31}$, te se time i određivanje $\mathrm{i}$ definisanje egzistencije dovodi $\mathrm{u}$ pitanje $\mathrm{u}$ tradicionalnom metafizičkom smislu.

Druga bitna stvar koju Gaset nagoveštava je da je do progresivne de-realizacije sveta došlo ne samo u umetnosti već i u filozofiji i da se to događalo simultano kroz epohe: „Vodeći zakon velikih slikovnih varijacija je uznemiravajuće jednostavan. Prvo su se slikale stvari; kasnije senzacije i na samom kraju ideje. To znači da je pažnja umetnika počela da se upravlja prema realnosti; kasnije prema subjektivnosti i na kraju

29 Prole, Dragan. „Redukcija u fenomenologiji i slikarstvu“ u:. Годишњак Филозофског факултета у Новом Саду, 41(2016)2. str. 75.

${ }^{30}$ Gasset, José y Ortega. Sobre el punto de vista en las artes. Revista de Occidente, 1929., p. 129.

${ }^{31} \mathrm{Za}$ razliku od modernosti koja je insistirala na razlici između tzv. ,primarnih“ $\mathrm{i}$ „sekundarnih“ kvaliteta predmeta koja je osnova za promišljanje supstancijalizovane realnosti. 
prema intersubjektivnosti. “32 Po Gasetu, posledica pomeranja tačke gledišta je ukidanje transcendensa i potpuno subjektiviranje sveta, koje je i na samom kraju od interiorizacije prešlo u eksteriorizaciju u intersubjektivnim konstrukcijama: „Filozofu ovo još više zaokuplja pažnju, i umesto da je usmeri na subjektivnost kao takvu, on je preusmerava sa ono što se do sada zvalo „sadržaj svesti“, intersubjektivnost. Ono što naše ideje ideiraju, što naše mišljenje misli, ne odgovara više ničemu realnom, ali ne znači zbog toga da je ono puko subjektivno. “33 Iako pokazuje da je došlo do de-realizacije u modernom smislu, on pravi otklon od ideje da „puka subjektivnost“ može biti kriterijum za istinu. U tom kontekstu ovaj tekst može da se tumači iz perspektive huserlovskog srednjeg perioda u kome je on razvio ideju inter-subjektivnosti u kontekstu transcendentalne filozofije.

Za razliku od Huserla, Gaset - iako usvaja ideju intersubjektivnosti - potpuno dovodi u pitanje mogućnost da se stvarnost promišlja u celini. On govori o tome kako realnost predstavlja prelamanje horizonata, od pojedinačnih do opštih realnosti. Drugim rečima, Gaset pokazuje da postoji realnosti onoliko koliko postoji subjektivnosti $i$ intersubjektivnih značenjskih relacija kojima se zahvata svet. Savremeni svet je Lajbnicova monadologija bez Boga. Ne postoji ona jedna monada koja je u stanju sve da percipira i sve da drži u jedinstvu. Sve što postoji je mnoštvo interpretacija realnosti od kojih je svaka manje ili više bliska „duhu vremena“. U tom kontekstu „puka subjektivnost“ je najdalje od istine jer je ona $\mathrm{u}$ interakciji sa drugima samo kao puki mimetičar realnosti. Tako može da se razlikuje subjektivnost koja ,jasnije percipira" realnost od one koja živi uronjena u sliku sveta koja joj se servira iz laži sadašnjeg vremena. Gaset daje i zanimljiv lajbnicovski primer: ${ }^{34}$ ako zamislimo da je svet piramidalnog karaktera, i da je najviša tačka piramide svevideća tačka gledišta (Bog), onda sve druge perspektive nastaju niže od ove tačke. Još, čovek kao monada nikada ne može biti ta, apsolutna tačka. Sve što postoji na „nižim ontološkim stupnjevima“ jeste „niži stepen percepcije“ koji se prelama sa drugim

\footnotetext{
${ }^{32}$ Prev. i podv. autor. Isto, str. 126.

${ }^{33}$ Podv. autor. Isto, str. 148.

${ }^{34}$ Ortega y Gasset, José and Talbot, Toby. The origin of philosophy. p. 51.
} 
monadama i tako tvori sopstvenu istinu. Ipak, najviši stupanj iz perspektive ograničene monade nije imanje jedinstva svega, nego mogućnost sebe-zahvatanja, apercepcije u tom procesu. On paradoksalno pokazuje da je najprimitivnija subjektivnost ona koja nikada nije sebe mislila, sebe stvorila i slobodno odlučila, dakle ona koja nije stvorila sopstvenu individualnost, sopstveni identitet. ${ }^{35}$ On primitivizam vezuje za „lošu opštost“ i verovanje u imanje apsolutne istine ${ }^{36}$. U tom kontekstu pravi pomalo ničeansku razliku između čoveka stvaraoca i čoveka stada, mase. Ta razlika je vidiljiva u načinu odnošenja prema umetničkim delima, ali i kao jedna kulturna pojava, način samog života pojedinca.

\section{MASE I MASOVNA UMETNOST}

„Masovnost“ savremenog sveta valja razlikovati od prethodnog poimanja tog pojma. Nije reč više samo o grupama ljudi koji žive na istoj teritoriji i dele neke slične ideje, kulturološke okvire i način života. Differentia specifica u odnosu na prethodne epohe nije jedan već nekoliko faktora koji odeljuju savremenost od prethodnih etapa. Za početak, globalizacija koja predstavlja proces povezivanja i umrežavanja na globalnom planu. Razobručenje kultura se dešava spontano pod sudarima različitih dominantnih obrazaca življenja. Na to je naravno uticalo razviće tehničkog sveta na čijoj platformi mogu sve brže da se prenose informacije. Industrijalizacija, laki prenos ljudske radne snage, ili ekonomskim rečnikom „ljudskih resursa“ doprineo je takođe sve većoj mobilnosti i pokretljivosti radnika. Razviće masovnih medija koje je doprinelo prenosu informacija i u pozitivnom i u negativnom kontekstu.

\footnotetext{
${ }^{35}$ Ortega y Gasset, José. En torno a Galileo, Esquema de la Crisis, p. 38.

${ }^{36}$ Posao filozofa je da gradi principe u promenjivoj realnosti. Dakle, nije rešenje prepustiti se nihilizmu, već izgraditi svet na temelju sadašnjosti: „Filozofija je oformljavanje kretanja koje vodi do izlaska iz sumnje. Bez toga nema filozofije. Zbog toga se ne gradi na čuđenju nad stvarima koje su date u njenom neopsrednom ambijentu i svetu. Zbog toga filozofija nema primarno direktan odnos prema svetu, već se vraća određenim idejama i 'modusima mišljenja' koji su dati u 'preegzistenciji'“". Gasset, José y Ortega and Takeru Sugiyama. La idea de principio en Leibniz y la evolución de la teoría deductiva. Revista de occidente, 1979 , p.137.
} 
Uspon nauke, racionalizacija, operabilnost, itd. samo su neki od osnovnih obeležja savremenog sveta.

Gaset u kontekstu tog sveta razmatra fenomen masa koje pate od nedostatka fantazije. Po njemu mase je najteže objasniti filozofski, zato što je skoro nemoguće napraviti ontološki okvir u koji bi se one smestile. $^{37}$ Mase odlikuje nemogućnost da samo-inicijativno donose odluke, stvaraju, odlučuju. One žive i rade stihijski, pod plimama i osekama trenutnih dešavanja. Čovek mase nije čovek stvaralac, već mimetičar koji ne ulaže napore da osmisli život, već samo podržava ono što je trenutno usvojeno kao vladajući sistem vrednosti. Tako je čovek mase, dok može da ostvari svoje interese, stihijski prepušten sadašnjosti, a u trenucima kada to više ne može podleže nasilnim pokušajima da sprovede sopstvene namere. Njegov pogled na svet je „uzak“, što znači da i odluke koje donosi nemaju suštinski u vidu širi značaj za zajednicu nego samo ostvarenje sopstvenih banalnih namera. ${ }^{38}$ Sa druge strane, postoji čovek elite, kojeg valja shvatiti šire od ekonomske kategorije. To je čovek koji je primarno stvaralački nastrojen u pokušajima da osmisli za početak vlastiti život, a onda po potrebi i život zajednice u kojoj se nalazi. Ono što Gaset paradoksalno pokazuje to je da je čovek primordijalno svakako stvaralac. Nastavljajući filozofsku tradiciju egzistencijalizma, koja pokazuje da egzistencija prethodi esenciji, treba da se pokaže da čovekov zadatak nije više primarno saznajno-metafizički već kreativnostvaralački: čovek je stvaralac sopstvenog života, bilo da je originalni novelista ili plagijator. ${ }^{39}$

Mase odlikuje nemogućnost da stvore, kreiraju, projektuju vlastiti svet unapred, zbog toga ne mogu pravilno ni da odgovore na krizu kada ona nastupi. ${ }^{40}$ Ako se posmatra odnos masa prema umetnosti savremeno društvo se takođe razlikuje od prethodnih perioda. Umetnost se „uvlači“ u

${ }^{37}$ Prev. i podv. autor. Gasset, José y Ortega. La rebelión de las masas. EspasaCalpe. 1964, p.12.

38 Detaljnije o tome: Krznar, Tomislav. „Čovjek mase ili o ulozi filozofije u obrazovanju; Uvidi Ortege y Gasseta."Filozofska istraživanja, Zagreb, 35 (2016) 4, str. 648.

${ }^{39}$ Gasset, José y Ortega. Historia como sistema. Espasa-Calpe, 1971, p.14.

$40 \mathrm{Zbog}$ toga se $\mathrm{u}$ političkom smislu u kriznim periodima priklanjaju fundamentalizmu. 
šire krugove i deluje da ona postaje dostupna svima. Svako ima osećaj da može da tumači umetnost, i još, kako je to Vorhol najavio, svako dobija priliku da bude bar na kratko vreme i sam slavni stvaralac. Moderni zahtev da svako treba da ima hrabrosti da se služi sopstvenim razumom menja se imperativom da svako treba da se služi sopstvenom fantazijom. I onda se postavlja pitanje koja tačka treba da bude tačka razlike između vrednih umetničkih dela i onoga što je umetnost kao posledica masovne proizvodnje? Nije li umetnost uvek već u nekoj tački bila podložna reprodukciji, kopiranju? Nije li već Platon pokazao da je njena suština u osnovi mimetičkog karaktera, dok originalnost predstavlja područje rezervisano za nauku i filozofiju? Može li da se kaže da je savremena monadološka kultura mimetička kultura? Adorno pravi razliku između avangardne i masovne umetnosti, te pokazuje da se čini da savremena umetnost može da se podeli upravo na ta dva pola. ${ }^{41}$ Gaset bi se u potpunosti složio sa ovom podelom, te pokazao kako se „nova“ avangardna umetnost upravo razlikuje od onoga što je produkt masovne proizvodnje. Za početak pogledajmo šta bi to uopšte bila masovna umetnost i koje su njene karakteristike.

Masovnu umetnost odlikuje nekoliko karakteristika. Njena primarna odlika je da je dostupna masama. Dostupnost se postiže zahvaljujući novim načinima reproduktibilnosti i kopiranja sadržaja. Sam sadržaj u masovnoj proizvodnji nema veći značaj jer ne predstavlja svakako originalno umetničko delo, već najčešće kopiju istog. Razlika masovne umetnosti od prethodnih perioda je što ona biva dizajnirana tako da bude konzumirana od strane velikog broja ljudi. Njena primarna uloga nije dosezanje istine ili komunikacija sa opštim idejama vlastitog vremena, već, naprotiv, njena svrha je zabava. Još jedno njeno bitno svojstvo je to što ona biva dostavljena ljudima posredstvom masovnih medija. ${ }^{42}$ C̆ak i „najveća dela istorije umetnosti“ bivaju dostupna muzejima koji takođe postaju masovne institucije. O njoj može da se govori na temelju ideje reproduktibilnosti kao što to radi Valter

41 Adorno, Teodor. The culture industry, Selected essays on mass culture, Routledge, London-New York, 1991, p. 74.

${ }^{42}$ Carroll, Noël. „The Ontology of Mass Art“ in: The Journal of Aesthetics and Art Criticism, 55 (1977) 2, p. 188. URL: https://www.jstor.org/stable/431263 
Benjamin. Umetnička dela su uvek bila podložna kopiranju, međutim, tehnička reprodukcija ipak predstavlja novost u celom tom procesu. ${ }^{43}$ Grci su takođe reprodukovali umetnička dela, ali manualno, livenjem i štampanjem, dok savremeni tehnički svet donosi višestruko brži i efikasniji način reprodukcije koji čini da umetnost postaje sve više dostupna masama. Da bi bila autentična, umetnost bi ipak morala da komunicira sa opštim idejama - bile one shvaćene kroz običajnost, mitologiju, politiku. Masovna umetnost se zasniva na mimesisu čiji cilj nije ostvarivanje inovativnog novuma, već upravo kopiranje i podražavanje već postojećih sadržaja. Mimesis, ukratko, nema intrepretativnu moć. ${ }^{44}$ Zbog toga je ta vrsta umetnosti primamljiva većinskom čoveku mase čiji stil života predstavlja ,idenje linijom manjeg otpora“ i čija je primarna uloga da upotpuni slobodno vreme na što bezbolniji način. Čovek mase je „tehnički čovek“, kako to Gaset pokazuje, i njegove akcije nikada nisu direktne. ${ }^{45}$ Kod čoveka mase je najtragičnije to što on ima potenciju za preobražaj koja ostaje neiskorištena usred vlastite ne-brige za sopstvenu egzistenciju.

Za razliku od masovne umetnosti, avangardna umetnost je izrazito ne-popularna. Ona nikada nije bila privlačna većem broju ljudi upravo zbog načina i forme u kojoj se pojavljuje. Dehumanizovana osobina je čini otuđenom i nezanimljivom većem broju ljudi jer je za njeno razumevanje i udubljivanje potreban napor. Da bi se umetničko delo pravilno interpretiralo, potrebna je posmatračka distanca, nešto slično kantovskom bezinteresnom posmatraču. Gaset pokazuje da je masovna umetnost takođe vrlo popularna jer ne smera na interpretaciju od strane pojedinca, već samo na afekciju i emotivni nadražaj. Pogrešno se pretpostavlja da je uloga tumača umetničkog dela da se identifikuje sa likovima u filmu, pozornici, platnu: „Ali umetničko delo je umetničko samo dotle dok se ne uzima kao nešto zbiljsko. “46 U objašnjenju uloge

\footnotetext{
43 Benjamin, Walter. The work of art in the age of its technological reproducibility, and other writings on media. Harvard University Press, London, 2008., p.21.

${ }^{44}$ Benjamin, Andrew. Art, mimesis and the avant-garde: aspects of a philosophy of difference. Routledge, London, 2005., p. 18.

${ }^{45}$ Gasset, José y Ortega. La rebelión de las masas, p.30.

${ }^{46}$ Gaset, José y Ortega. Dehumanizacija umetnosti i drugi eseji, str. 20.
} 
tumača dela Gaset naizgleda poistovećuje ljubitelja umetnosti sa stvaraocem. Da bi neko pretendovao uopšte da bude interpretator dela mora imati u vidu sve moguće različite perspektive koje se tu mogu pojaviti. Na postoji tako nešto kao što je neutralna tačka gledišta, ali se čovek približava interpretaciji imajući u vidu mnogoznačnost perspektiva koje se pojavljuju u delu kao i u životu. To znači da kada umetnik želi da predstavi neku ličnost, ili nešto, nije važno samo to šta on jednoznačno predstavlja, nego treba uzeti u obzir i tačku gledišta samog umetnika. Ta tačka biva naknadno uvučena u proces interpretacije.

Kako se pokazuje, način na koji su avangardna dela stvarana i predstavljana čini ovaj pokret izrazito nepristupačnim za tumačenje. Ona je estetski i moralno izazovna, te potpuno nedostupna onima koji nemaju bar neku vrstu pred-znanja koje je neophodno za njihovo pravilno tumačenje i razumevanje. ${ }^{47}$ Gaset smatra da je avangarda radikalno drugačija od svih drugih istorijskih škola i pokreta. Zbog toga je razlikuje i spram romantizma. ${ }^{48}$ Romantičarske ideje se lako uvlače u masovnu i popularnu umetnost, jer njihova osnova nije istorijski prikovana. Romantizam kao takav nije problematičan, već upravo potencija da se neke od njegovih osnovnih ideja učine popularnim masama. Ta potencija dolazi iz činjenice da neke od tih ideja smeraju na komunikaciju sa „osećanjima“, pa umesto da ljudi uživaju u delu uživaju u sopstvenom narcisoidnom odnosu: u svojoj emociju koju delo izaziva. ${ }^{49}$ Ne slažu se naravno svi autori sa ovom Gasetovom konstatacijom. Pokazuje se da romantizam i avangarda imaju čak mnogo više sličnosti nego što je to moguće na prvi pogled videti. ${ }^{50}$ Osnovna je razlika u njihovoj (ne)popularnosti u savremenom dobu, ali ne sme se zaboraviti da

\footnotetext{
${ }^{47}$ Carroll, Noël. „The Ontology of Mass Art“ in: The Journal of Aesthetics and Art Criticism, p. 190.

48 „U tom duhu, zaboravlja se da umetnost nije izlovan fenomen, već da je deo mnogo šireg socijalnog konteksta. Prema Bürger-u Aufhebung umetnosti u doba renesanse je 'lažan' zato što ideal ne može biti dostignut u 'buržoaskom društvu', uprkos 'pathos-u istorijske progresivnosti' koje ono nosi sa sobom. “ u: Doorman, Maarten. „From Romanticism to the Avant-Garde“, in: Art in Progress. Amsterdam University Press. (2003), p. 55 URL: https://www.jstor.org/stable/j.ctt46mz0k.

${ }^{49}$ Gaset, José y Ortega. Dehumanizacija umetnosti i drugi eseji, str. 45.

${ }^{50}$ Poggioli, Renato. The Theory of the Avant-garde, p. 50.
} 
romantizam u umetnosti u svoje vreme takođe nije bio dostupan svima, a da avangarda što više vreme odmiče postaje primamljiva masama.

\section{ČOVEK JE HOMO VIATOR, SVET NEMA POČETAK NI KRAJ}

Paradoksalno se pokazuje da iako se kod Gaseta čovek shvata primarno kao stvaralačko biće, u kontekstu umetnosti ovaj pojam više nije dominantan. Čovek sve što ima od sveta jesu on i njegove okolnosti. ${ }^{51}$ Zbog toga je njegov primarni zadatak da oblikuje sopstveni život u skladu sa horizontom onoga što zahvata. Čovek više nije shvaćen kao homo faber, što bi bio moderni redukovani smisao pojma stvaralaštva, već se shvata kao putnik. Ideja čoveka putnika je takođe stara hrišćanska ideja. Možda može da se kaže da Hajdeger čoveka shvata slično, kao biće koje je bačeno u svet. Gaset ovu ideju preobražava u novom maniru savremene krize filozofije i umetnosti. Iako njegove ideje podsećaju na ničeanski shvaćen nihilizam, Gaset smatra da evropsku tradiciju i istoriju ne treba kritikovati, već pokazati odakle upravo postoji potreba da se filozofski i umetnički misli i da se traži bivstvo svih bića. Ta potreba je najdublja životna potreba čoveka da se orijentiše u svetu koji je za njega nepoznanica u svojoj celini. Biti na putu znači tražiti uvek iznova iz novih okolnosti novu istinu, novu filozofiju, novu umetnost. To ne znači ukinuti duhovne oblike mišljenja. Gaset smatra da čak i istorija podleže intrepretaciji. ${ }^{52}$ Interpretacija znači da postoji nešto zajedničko monadama koje egzistiraju, a to je svet života $\mathrm{i}$ iskustvo na koje se odnose (circumstancia). Međutim, sam horizont se uvek iznova kreira, ili hegelovski rečeno, duh vremena nije nešto što unapred može biti zadato. On se iz sadašnje tačke reflektuje. On se u procesu života stvara. Za Gaseta ne bismo mogli da kažemo da je nihilista, jer čak i kada bi prihvatio ničeansku tezu „bog je mrtav“, on bi rekao da novog boga valja stvoriti, da je to zadatak umetnika i filozofa. Razlika spram dugih perioda je svakako to što sada u proces stvaranja čovek ugrađuje i sebe kao stvaraoca, kao biće potencijalnosti i mogućnosti. U tehničkom svetu

${ }^{51}$ Čovek je jedino biće koje može od okolnosti da stvori priliku. Upor: Marcel, Gabriel. Homo viator, Henry Regenery Company, Chicago, 1951, p. 23.

${ }^{52}$ Gasset, José y Ortega, Sobre el punto de vista en las artes., p. 129. 
deluje da je u procesu reproduktibilnosti pojam mogućnosti i stvaranja u najširem smislu zanemaren. Ali ipak u zaključku valja reći da čovek nikada neće prestati sebe da reflektuje i da stvara, čak ni onda kada više sebe ne shvata primarno kao stvaraoca: „Neka onda čovek kaže kada će doći taj dan kada će poslednji put zabrujati sirena na fabrici rada, kada će naučni tehnikum reći da je sve završeno, da je poslednja smena, da je 'sve' poznato, i kada će čovek na fabrici viknuti - dosta, rad je završen, sve je istraženo. Ja sam na vrhu svetova, odnosno, ja sam upio svetove, ovladao sam svim savršenstvima, 'ja sam Bog'“. 53

\section{LITERATURA}

Adorno, Teodor. The culture industry, Selected Essays on Mass Culture, Routledge, London-New York, 1991.

Aristotel. Nikomahova etika, Izdavačka knjižarnica Zorana Stojanovića, Sremski Karlovci-Novi Sad, 2013.

Benjamin, Andrew. Art, mimesis and the avant-garde: aspects of a philosophy of difference. Routledge, London, 2005.

Benjamin, Walter. The work of art in the age of its technological reproducibility, and other writings on media. Harvard University Press, London, 2008.

Buber, Martin, and Eugenio Ímaz. ¿ Qué es el hombre?. Fondo de Cultura Económica, Mexico, 1949.

Carroll, Noël. „The Ontology of Mass Art“ in: The Journal of Aesthetics and Art Criticism, 55 (1977) 2, pp. 187-199. URL: https://www.jstor.org/ stable/431263

Doorman, Maarten. „From Romanticism to the Avant-Garde“, in: Art in Progress, Amsterdam University Press. 2003, pp. 45-59.URL: https://www.jstor.org/stable/j.ctt46mz0k.

Eriugena, Johanes. „O podeli prirode“, u: Od Aristotela do renesanse, Nakladni zavod Matice hrvatske, Zagreb, 1982.

Gaset, José y Ortega. Dehumanizacija umetnosti i drugi eseji, LITTERIS, Zagreb, god. 2007.

Gasset, José y Ortega. En torno a Galileo, Esquema de la Crisis, Revista de Occidente, 1976.

Gasset, José y Ortega. Historia como sistema. Espasa-Calpe, 1971.

${ }^{53}$ Maljevič, Kazimir Severinovič. Bog nije zbačen. Zadruga praksa, Pula, 2015, str. 34. 
Gasset, José y Ortega. Ideas y creencias. Revista de Occidente, Madrid, 1934.

Gasset, José y Ortega. „¿Qué es filosofía?“, en: Obras Completas, Revista de Occidente, 405(1969)8, Madrid.

Gasset, José y Ortega, and Takeru Sugiyama. La idea de principio en Leibniz y la evolución de la teoría deductiva. Revista de Occidente, 1979.

Gasset, José y Ortega. Sobre el punto de vista en las artes. Revista de Occidente, 1929., p. 129-148.

Gasset, José y Ortega and Talbot, Toby. The origin of philosophy. New York: North \& Company, 1967.

Habermas, Jürgen. „Modernity - An Incomplete Project“", in: Foster, H. The antiaesthetic: Essays on postmodern culture, Bay Press, Washington, 1983.

Heidegger, Martin. Kant i problem metafizike, Mladost, Beograd, 1979.

Husserl, Edmund. Ideja fenomenologije, pet predavanja, Beogradski izdavačkografički zavod, Beograd, 1975.

Huserl, Edmund. Kartezijanske meditacije 1, Centar za kulturnu delatnost Saveza socijalističke omladine, Zagreb, 1975., str. 142.

Kantarberijski, Anselmo. „Proslogion“, u: Quid vere sit Deus, Demetra, Zagreb, 1977, str. 155.

Krznar, Tomislav. „Čovjek mase ili o ulozi filozofije u obrazovanju; Uvidi Ortege y Gasseta.“ u: Filozofska istraživanja, Zagreb, 35 (2016) 4, str. 645-656.

Maljevič, Kazimir Severinovič. Bog nije zbačen. Zadruga praksa, Pula, 2015.

Poggioli, Renato. The Theory of the Avant-garde, Cambridge, Harvard University Press, 1968.

Prole, Dragan. Pojave odsutnog, Izdavačka knjižarnica Zorana Stojanovića, Novi Sad-Sremski Karlovci, 2016.

Prole, Dragan. „Redukcija u fenomenologiji i slikarstvu“ u:. Годишњьк Филозофског факултета у Новом Саду, 41(2016)2, str. 67-77.

Rajković, Marica. „Kraj umetnosti kao početak estetike“, u: Estetika $i$ obrazovanje, Estetičko društvo Srbije, Beograd, 2011., str. 15-35.

Rajković, Marica. „Umetnost i duh vremena“, u: Kriza umetnosti $i$ nove umetničke prakse, Estetičko društvo Srbije, Beograd, 2014, 239-261. 


\author{
TANJA TODOROVIĆ \\ University of Novi Sad, Faculty of Philosophy
}

\title{
PHANTASY AND CREATIVITY IN PHILOSOPHY OF ORTEGA Y GASSET
}

\begin{abstract}
Ortega y Gasset's philosophical inheritance is not systemically conceived. Therefore, the notions of fantasy and creativity in this paper are interpreted in the framework of his ontological research and in the context of his reflections on the "new", "young", avant-garde art. It shall be shown that his concept of fantasy is not understood in a traditional way, as a special "organ" or a moment in the epistemological scheme, but as one of the fundamental ways in which man relates to the world. Man is understood as a homo viator whose task is to interpret his own reality. Having a phantasy, man is being able to set an interpretive attitude towards life, and in the contemporary world he also has this attitude towards works of art themselves. On the other hand, we shall set off his critique of the notion of creativity based on the philosophy of art, and show the reaffirmation of this notion in the context of the rational-vitalist position.
\end{abstract}

Keywords: dehumanization, fantasy, interpretation, Ortega y Gasset, masses, creativity

Primljeno: 22.2.2020.

Prihvaćeno: 6.5.2020. 